\title{
Policy Analysis of Suppression and Mitigation Strategies in the Management of an Outbreak Through the Example of COVID-19 Pandemic
}

ilker Kayı ${ }^{\mathbf{1}}$, Sibel Sakarya ${ }^{\mathbf{1}}$

1 Department of Public Health, Koç University School of Medicine, Istanbul, Turkey

\begin{abstract}
Objective: The objective of this study is to review the containment approaches adopted by countries to control COVID-19 pandemic. In our analysis, we have used Bacchi's framework for interpretive policy analysis and examined the measures countries have taken and discussed the premise underlying containment strategies. We have included in our analysis United States of America, United Kingdom, Netherlands, Sweden, Denmark, Norway, Germany, Italy, Turkey, South Korea, Singapore, Japan and China.

There are essentially two strategies that are used in the management of an outbreak: suppression or mitigation. Suppression strategy aims to lower the basic reproduction number (Ro) below 1 and thereby reduce the number of infected people or eliminate the person-to-person transmission. Mitigation approach, on the other hand, aims to generate community (herd) immunity by allowing the controlled infection of people. In this approach, the aim is not to bring Ro under 1 but to mitigate the health effects of the outbreak. It is seen that given the epidemiological features of the disease, the scope of the virus, and the limitation of the intervention resources at hand, the suppression approach is accepted more widely by the countries in terms of Covid-19 pandemic. In contrast, the mitigation strategy is approached with suspicion. The approach aiming to achieve herd immunity seems more suitable for situations in which it is possible to protect the high-risk groups by administrating vaccine.

These evaluations should be carried out following the circumstances of the country in question. It is essential to form an evidence-based plan that is appropriate for the national context. It should be kept in mind that the solutions for the fight against the virus do not solely consist of those ready-made implementations by choosing one option over the other and that mixed models could be brought to the agenda when required.
\end{abstract}

Conclusion: epidemics, immunity, herd, health policy, infection control

\section{INTRODUCTION}

I $\mathrm{n}$ the statement he gave to the television program Nieuwsuuer on March 16, Sunday evening, the Head of Dutch National Institute for Public Health and the Environment (RIVM) Jaap van Dissel maintained that 'an approach of total lockdown would lead the COVID-19 to bounce back' and thereby they would employ the 'maxi-
Corresponding Author: ilker Kayı

\section{E-mail:}

ikayi@ku.edu.tr

Received: April 24, 2020 Accepted: April 29, 2020 Published: April 30, 2020

Suggested citation: Kayı I, Sakarya S. Policy Analysis of Suppression and Mitigation Strategies in the Management of an Outbreak Through the Example of COVID-19 Pandemic. Infect Dis Clin Microbiol 2020; 1: 30-41.

DOI: $10.36519 / \mathrm{idcm} .2020 .0009$ 
mum control' strategy. Some $50 \%$ to $60 \%$ of the 17.4 million people in the Netherlands would have to catch COVID-19 to reach a level of herd immunity (1). Van Dissel stated that they based their predictions on the way the virus spread, and they intended to make the virus circulate among people who would have little problem in case they were infected, while at the same time, they would protect the vulnerable groups as much as possible. That is how the Dutch National Institute for Public Health and the Environment has announced they adopted the approach of 'maximum control' or 'mitigation' for the COVID-19 pandemic.

This 'mitigation' approach, which was previously adopted as a containment policy by the Sweden, Netherlands and until recently the United Kingdom (UK) has drawn severe criticisms. While most of the other European countries have imposed tight quarantine measures, the UK government has advised its citizens to remain calm and carry on with their daily lives. This approach was defended by Sir Patrick Vallance, England's Chief Scientific Adviser who was of the opinion that the best way of mitigating the longterm consequences of the coronavirus pandemic was to allow the natural spreading of the virus in an effort to acquire herd immunity (2). The researchers who synchronously work at Imperial College London and London School of Hygiene and Tropical Medicine have evaluated the effect of 5 measurements that are listed below both separately and in combination with

\section{HIGHLIGHTS}

- Simulation models have been applied to predict the outcomes of the epidemic; however, it should be kept in mind that input variables for COVID-19 has been shown to be uncertain or absent due to the novel nature of the disease.

- Deciding which one to adopt between mitigation and suppression strategies do not necessarily require choosing one of these approaches, but rather considering the context and choosing the right interventions during the process.

- Decision making during such a novel epidemic should be based on scientific evidence, therefore there is a need to develop an infrastructure for producing quality data. each other by means of mathematical modelling relying on the case of Italy. These measurements are as follows: case isolation (7 days), home-quarantine (14 days), social distancing (the reduction of general contact up to $3 / 4$ ), social distancing only for people over 70 , and the closure of schools and universities (3). This modelling study had illustrated that even when only those measures were taken to mitigate the outbreak, $30 \%$ of the hospitalised patients would need intensive care unit, which meant exceeding the capacity of National Health System (NHS). On the basis of these evidences, the UK government abandoned the mitigation approach and announced more strict measures to suppress the outbreak (4).

This study aims to explore the reasons behind herd immunity approach utilized by some countries as a COVID-19 outbreak containment strategy. Our focus was on how and why certain policies come to be developed in particular contexts, by who, for whom, based on what assumptions and with what effect

\section{METHODS}

This study provides an interpretive policy analysis of containment approaches adopted by countries to control COVID-19 pandemic. Representation and framing of the problem are at the centre of interpretive policy analysis (5). We have explored suppression and mitigation approaches as two main containment strategies that are discussed globally. In our analysis, we adopted Bacchi's framework for interpretive policy analysis (6), and we used the following questions from this framework:

1. What is the problem represented to be in the debate between defenders of mitigation or suppression strategies?

2. What presuppositions or assumptions underlie this representation of the problem? It refers to the background knowledge and key concepts explaining the problem.

3. How has this representation of the problem come about? The goal is to examine the history and mechanisms in the process that shape the current problem representation over time. 
4. What is left unproblematic in this problem representation? This inquiry aims to identify the limitations of problem representations so that it focuses on contradictions arising by the representation.

5. What effects are produced by the representation of the problem?

By using the framework as Bacchi (2009) described (6), we have analyzed the containment strategies of countries such as United States of America, United Kingdom, Netherlands, Sweden, Denmark, Norway, Germany, Italy, Turkey, South Korea, Singapore, Japan and China. We have made a thorough search on internet for discursive materials found in news websites and scientific journal newsletters provided in English. The policy orientation of countries was derived from official position statements by the government officials and problem definitions by public health experts providing opinion on the suppression and mitigation subject. We have analyzed the measures countries have taken and discussed the premise underlying containment strategies.

\section{FINDINGS}

\section{What is the problem represented to be?}

Governments all around the world depending on their resources are struggling to control the COVID-19 pandemic that has started in Wuhan, China. As a containment strategy, some of the countries have announced that they will be taking milder preventive measures such as the Netherlands, Sweden and the UK at first. Acknowledging that an attempt to summarize what a policy tries to solve as a problem may vary due to the complex and interrelated nature of problematic conditions, it can be said that although the approaches with regard to the prevention of infectious diseases have changed since the Influenza Pandemic of 1918, there are essentially two strategies in controlling an outbreak: suppression and mitigation (3). However, the mitigation strategy took huge criticism from prominent epidemiologists. Nevertheless, countries such as Sweden decisively continues its mitigation strategy (7).
What presuppositions or assumptions underlie this representation of the problem? Suppression strategy aims to lower the basic reproduction number $\left(R_{0}\right)$ below 1 and thereby reduce the number of infected people or eliminate the person-to-person transmission (as it was done for SARS and Ebola). The second approach is 'mitigation.' This approach aims to generate community (herd) immunity by allowing the controlled infection of people. In this approach, the aim is not to bring $R_{0}$ under 1 but to mitigate the health effects of the outbreak. This approach was employed in some of the cities in the US in 1918, and the influenza pandemics of 1957, 1968, and 2009 (3). In the pandemic of 2009, high-risk people were protected by being vaccinated at an early period while the people outside of high-risk groups were informed about taking non-pharmaceutical preventive measures, and in this way, an attempt was made to control the outbreak.

In pandemic situations, where there is no vaccine or effective treatment, there are only two intervention areas. The first one is at the individual level consisting of diagnosis, supportive care and isolation of the patient and the prevention of complications and mortality. The second one, which is the prevention or the mitigation of transmission of the disease from each patient, is at the societal level. In the absence of pharmaceutical interventions, various combinations of the implementations indicated in Table 1 are implemented for the containment of the outbreak to stop person-to-person transmission.

The aim of mitigation approach is to control the outbreak by (a) flattening the curve, (b) allowing the controlled transmission of the infection among the low-risk groups as they have lower complications and mortality rate, and (c) protecting the high-risk groups (individuals with chronic diseases and elderly people) with maximum effort to prevent mortality. The overarching aim is to achieve herd immunity to prevent the emergence of new waves of the outbreak, and to avoid the social restriction and economic impact of the pandemic, which is probably the most commonly articulated reason for not employing the suppression approach. 
Table 1. The comparison of the goals and outbreak control methods of suppression and mitigation approaches (The information was gathered by the authors through examining the implementations of the countries)

\begin{tabular}{|c|c|c|}
\hline & Suppression & Mitigation \\
\hline \multicolumn{3}{|l|}{ Goal } \\
\hline Mortality & Minimize & Minimize \\
\hline Morbidity (incidence) & $\begin{array}{l}\text { Flatten the curve as much } \\
\text { as possible }\end{array}$ & $\begin{array}{l}\text { Flatten the curve to preserve } \\
\text { health system capacity }\end{array}$ \\
\hline \multicolumn{3}{|c|}{ Implementations during the control of the outbreak } \\
\hline Testing & Frequent & Frequent \\
\hline Contact tracing & Frequent & Frequent \\
\hline Case isolation & Frequent & Frequent \\
\hline Self-quarantine & Frequent & For those who display symptoms \\
\hline Travel Restrictions & Frequent & For high risk regions or countries \\
\hline Any sort of gathering & Postponement / Cancellation & Restricting the number of people \\
\hline Closure of primary schools & Frequent & Rare \\
\hline Closure of universities & Frequent & Often \\
\hline General Social Distance & Frequent & Often \\
\hline Restrictions for public spaces* & Frequent & $\begin{array}{l}\text { Depending on how the } \\
\text { outbreak progresses }\end{array}$ \\
\hline Social distancing for only high-risk groups & Rare & Prevalent \\
\hline Declaring curfew & Generally required & Rare \\
\hline
\end{tabular}

* Shutting down all the activities of public spaces and events such as cafes, restaurant, bars, shopping malls, and sports games. 
There are various definitions of the concept of herd immunity in the literature. For example, Fine (1993) defined herd immunity as the protection of populations from infection, which is brought about by the presence of immune individuals (8). A more functional definition by John and Samuel (2000) defined it as the proportion of subjects with immunity in a given population (9). Here the immunity can be acquired through having the disease (naturally acquired active immunity) or through vaccines (artificial active immunization). On the other hand, the concept of herd immunity has been started to be extensively used in the literature thanks to the vaccine research. Therefore, when the term herd immunity is used, it is generally understood to be herd immunity acquired through the vaccine. Another important characteristic of this definition is that it addresses the concept of immunity as an individual characteristic, and thereby turns it into a measurable parameter. In this way, the level of herd immunity can be calculated through a representative sample obtained from society.

\section{How has this representation of the problem come about?}

The emergence of the effect of herd immunity depends on the basic reproduction number of infectious agents. For example, the level of immunity required to prevent an outbreak caused by measles is $93.3 \%$ while this level is $66.6 \%$ for COVID-19. One of the reasons as to why the option of herd immunity has come to the fore in the control of Covid-19 outbreak is this relatively low threshold value despite the morbidity and mortality rate of the disease.

One of the basic tenets of mitigation strategy is the following: Since there is no vaccine or any effective treatment, social measures to contain the outbreak are the essential strategy. However, after the first wave of the outbreak, the disease can return in the form of a second wave when the social measures that have been taken are loosened or abandoned. In that case, the suppression approach should be put on the agenda once again, because the herd immunity would not have been achieved yet, and there would still be vulnerable groups in the society. This is defined as 'intermittent suppression' $(3,10)$.

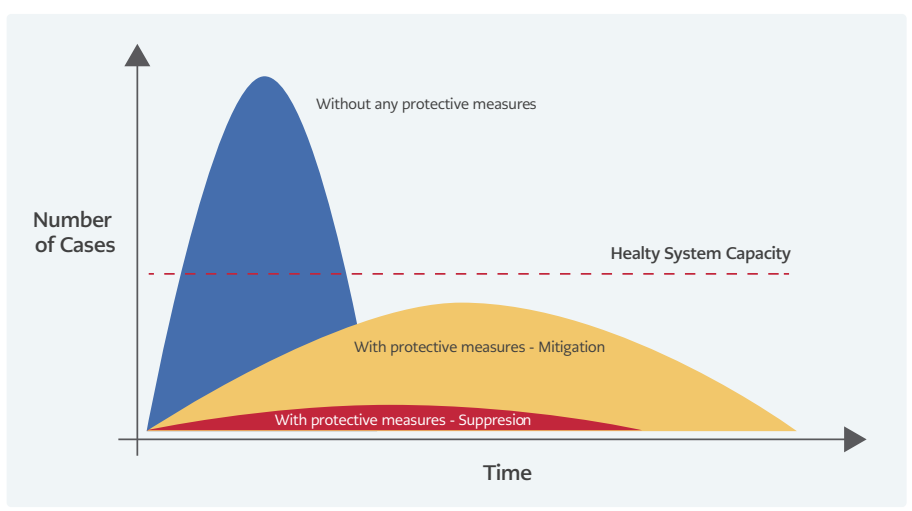

Figure 1.

Containment of the outbreak depends not only on the strength of the health care system but also the socio-economic policies put forward by countries as to how these implementations in Table 1 are combined and how rigidly they are applied. For example, strong primary healthcare service is required for carrying out effective contact tracing. China is one of the countries that successfully carried out contact tracing concerning Corona pandemic. Likewise, Singapore, Japan, and Hong Kong have shown the strength of their primary health care systems during COVID-19 pandemic. On the other hand, in the United States where primary health care is almost non-existent and the health system is highly dependent on secondary and tertiary care, large-scale contact tracing seems highly difficult to control the pandemic (11-12-13).

The effects of different strategies implemented in the control of the outbreak on the epidemic curves are shown in Figure 1. The capacity of a health care system is a significant variable in reducing complications and mortality rate. The capacity of the health care services refers to the number of physicians, nurses, hospital beds, and intensive care beds. Considered from this perspective, taking measures so as to flatten the curve in the containment of outbreaks will prevent exceeding the health system capacity (10) and ensure that people in need of care will receive those services appropriately. In cases where the overwhelming demand for health care services cannot be met, the physicians have to make choices among their patients as can be observed in the news coming from Italy (14). 


\section{What is left unproblematic in this problem rep- resentation?}

In the struggle against Covid-19 pandemic, the countries choose one of the two approaches mentioned above, and they can navigate their strategies by conducting further evaluations. The premise underlying suppression strategy is to prevent the high mortality of COVID-19. However, the major difficulty of suppression strategy is the need to sustain the non-pharmaceutical interventions until, for example, a vaccine is found. In the case of COVID-19, it is expected that this process will at least take 12 to 18 months. Besides, it is not guaranteed that the first vaccine will be effective, and in case there is a second wave of the outbreak, the suppression strategies might have to be repeated again.

Unlike past pandemics, there are more commonly used prediction tools to understand the impact of infectious diseases and outbreaks: Data science. These studies from different research groups try to support (a) decisions affecting disease transmission and interventions; (b) decisions regarding resource management; and (c) decisions about care (15). SEIR model (Susceptible - Exposed - Infectious - Recovered) has been the dominant model utilized by research groups since the beginning of the outbreak to understand the impact of mitigation and suppression strategies $(10,16,17)$. While many modelling studies on the impact of COVID-19 on health system capacity and mortalities recommend suppression as a containment strategy $(3,10$, 18), another study using a stochastic transmission model only suggested effective contact tracing and case isolation (19).

The challenge with the simulation models is the need for input variables which are uncertain or absent in the progress of COVID-19 outbreak (20). Currie et al. (2020) state that there are two types of uncertainties in simulation models which are input uncertainty and intrinsic variation in the process (15). In their study, Hellewell et al. (2020) addressed this uncertainty with a scenario of higher pre-symptomatic transmission or diagnostic delays which undermine the effectiveness of case isolation to control the outbreak successfully (19). Ionadis (2020) have also commented on the input variables such as $R_{0}$ and case fatality rates to be exaggerated and varied across nations. For example, while case fatality rates were $0.9 \%$ and $0.2 \%$ in South Korea and Germany respectively, it was taken as 3\% in general in these models (21). In another study Ionadis et al. (2020) evaluated the data from 8 countries and 4 US states and depending on their findings that deaths among people under 65 years of age without any chronic condition were highly uncommon they suggested a mitigation strategy focusing on protecting the elderly population to control the outbreak (22).

The history of achieving herd immunity as a control measure or infectious diseases started with vaccines (8). However, it is worth remembering that the herd immunity effect calculations are based on the assumption that the social structure is homogeneous, and the individuals meet through coincidental interaction. Additionally, there is a knowledge gap regarding how effective the short- and longterm immunity pattern of Covid-19 will be. Therefore, one needs to take into consideration whether there are groups with different characteristics in a given society and their interactional dynamics among each other when herd immunity is calculated, and modelling attempts are carried out. Calculations that are made in this manner might cause the threshold value for herd immunity to be higher than the calculated values.

In addition, non-pharmaceutical interventions to flatten the curve aims to decrease the transmission, which means decreasing $R_{0}$. This results in achieving required herd immunity level in a slower pace; therefore, calculations for the time to achieve herd immunity based on a scenario with no control measures (i.e. 66.6\% for COVID-19) will be misleading, even insufficient under certain thresholds of $R_{0}$ when the governments take action to mitigate or suppress the outbreak. A modelling study McBryde et al. (2020) for theAustralian context illustrated the varying levels of herd immunity based on targeted $R_{0}$ levels based on containment strategies (10). The authors have set the $\mathrm{R}_{0}$ target according to the health system capacity threshold and then compared the level of herd immunity to be achieved for each scenario. While a mitigation approach with an $R_{0}$ of 1.6 is reported to achieve a herd immunity level, $\mathrm{R}_{0}$ of 1.17 or a 
suppression target of 0.8 would be insufficient to prevent a second wave.

Dr William Hanage, an epidemiologist from Harvard University, wrote a piece on the UK's approach of herd immunity and stated that generating immunity in this manner is different from the immunity achieved by a vaccine. He indicated that people would actually become sick. In other words, what underlies the criticisms is the fact that the concept of herd immunity is based on 'the immunity achieved by vaccine.' However, in the case of COVID-19, the aim is to achieve this immunity through the transmission of the disease itself. According to Dr Hanage, even if one assumes that the virus was restricted to the low-risk population, at the peak of the outbreak the numbers requiring critical care would be greater than the number of beds available (23). Another criticism that Dr. Hanege directs at the approach of herd immunity with regard to Covid-19 pandemic is the lack of certainty that 'there will be a second wave, that the epidemic will be repeated in the future' as the people who defend the approach of herd immunity maintain. However, some recent publications have shared certain information that the second wave of the outbreak has already started (24). One of the reasons that make the herd immunity approach challenging is the evidence demonstrating that the disease is infectious in the asymptomatic stage (25), which makes it extremely difficult to protect the high-risk groups. Lastly, even though the mortality rate is expected to be quite low, many people will die since there will be a large number of sick people. Besides, given that this large number of sick people will inevitably lead to the overwhelming of the health system, it can be predicted that the damage will be greater than the projections.

The criticisms that were directed at the UK's policy of combating with the outbreak as it was first announced can also be assessed through a historical perspective. The views that Thomas Malthus voiced at the beginning of the $19^{\text {th }}$ century seem to be remembered in relation to the discussions of the mitigation approach. Malthus stated that the increase of the human population was not in parallel with the increase in agricultural production. He thus considered diseases, wars, and natural ca- tastrophes as instruments for striking a balance to ensure the continuity of life. Malthus also saw the attempts of controlling diseases (or outbreaks) as temporary efforts and as efforts that aimed to postpone the inevitable and that prepared the way for even more destructive consequences. Due to these views of Malthus, the view that the policies such as having more hospitals would lead to the continuation of irresponsible behaviour in society has become dominant and prevented the construction of more hospitals. This approach has remained effective for a long time in the UK in determining many of its policies (26).

Another area for discussion is the conflict between the free market economy embodied in the motto of laissez-faire and public health. One of the basic realities that the liberal and neoliberal policies that have been embraced since the $19^{\text {th }}$ century are based on is the elimination of the obstacles that prevent the entrepreneurs and investors from doing business. Even though the rationale behind this elimination is the distribution of income in favour of certain sections of the society, it is said that everyone will benefit from this situation thanks to the sustainability of economic growth. What state needs to do is to regulate this process instead of being a 'nanny' (27). The cessation of the countries' economic activities because of the outbreak is one of the fundamental obstacles for this desired growth. Therefore, it is required that the people who are part of the workforce and who are economically productive be allowed to continue their activities so that the economic activities could continue as well during the outbreak. Turkey has chosen a path to put legislation into force to ban outdoor activities for people over 65 and under 20 years of age with a limitation for the ones under 20 who need to work (28). The legislation targeting the people who are not participating in any economic activities or in other words those who are economically dependent on others subtly delineates the unspoken concerns of an economic crises arising because of public health measures to contain the outbreak. Although the idea of protecting the high-risk population groups that would be severely affected by the disease and allowing the people who would most likely have a mild condition so that they can continue their economic activities seems reasonable, the high mortality 
rate that is observed in Italy leads the governments to be torn between public health and economy.

\section{What effects are produced by the representation of the problem?}

The measures that have been taken when the outbreak first occurred in China resulted in the total lockdown of a state to the outside world and the obligation of its citizens to stay at their homes through the implementation of curfew. In the ongoing process, different countries have tried to control the outbreak by adopting different approaches.

According to the outbreak control methods indicated in Table 1, we can say that the Netherlands, the UK and Sweden implemented a mitigation approach at the beginning of the outbreak. Public Health Organizations in the Netherlands and the UK had publicly announced their approach in early March. About one week after this declaration, the UK has changed its strategy towards 'suppression' measures. The Netherlands proceeded with milder changes from mitigation to suppression in accordance with the course of the epidemic (29). Sweden maintains its mitigation approach: most places are open, only work hours are reduced, primary and secondary schools are open, people over 70 are particularly encouraged to stay at home, more than 50 people are prohibited from being together, and social distance rules are applied (30).

China, South Korea, Singapore and Denmark implemented suppression approach. Singapore, for instance, was one of the first countries to impose travel restrictions; applied draconian tracing and containment measures and showed a strong determination to implement these measures (31). Similarly, The Danish government declared a national lockdown and to close down its borders - following in the footsteps of Italy (32). Italy followed a suppression approach too, albeit with a delay. Suppression was the only option for Italy in the face of the sudden increase in the number of cases; as stated in an article, Italy followed the spread of the virus rather than prevented it (33). In Norway, on the other hand, comprehensive measures, such as the "Corona law", were undertaken in order to limit transmission of the virus and not overburden health and care services. Among these measures are clos- ing schools, universities and daily cares, a ban on cultural events, closed swimming pools, gyms, and all service provisions that involve physical contact with persons less than two meters away - with an exception for critical health care services. Finally, there is no cabin trip to the mountains, which is a huge deal and has spurred debate, whether it is a human right for Norwegians to go to their cabins. Responsibility to not overburden hospitals and risk putting healthcare workers in difficult ethical dilemmas is placed on the collective, a national dugnad (34).

Other countries we analyzed used different combinations of control measures, corresponding to the mitigation and suppression approaches presented in Table 1. The extent and severity of the measures taken by these countries have varied depending on the progress of the outbreak. For example, Turkey has never enforced a complete lockdown. However, in the early period of the epidemic, curfew was imposed for selected age groups, travel restrictions were implemented, and people were encouraged to stay at home unless necessary. In the later stages of the outbreak, curfews began to be imposed on all weekends for all citizens.

In Figure 1 and Figure 2, we present the number of cases and deaths reported in the countries we have analyzed and whose outbreak control approaches are described. In the end, as the State Epidemiologist of Sweden Anders Tegnell puts, it is still early to conclude on which strategy will provide better outcomes (7).

\section{DISCUSSION}

One thing to remember is that neither mitigation nor suppression approaches is choices on the opposite edges. In the presence of a strong surveillance system, it might be possible to successfully identify infected people, carry out contact tracing, and ensure isolation work properly in addition to using the approaches of mitigation and suppression together based on the continuous assessment of data. Additionally, it is necessary to act in accordance with universal norms on social and administrative levels to increase the trust of the society, ensure that the people will comply with measures, and achieve 


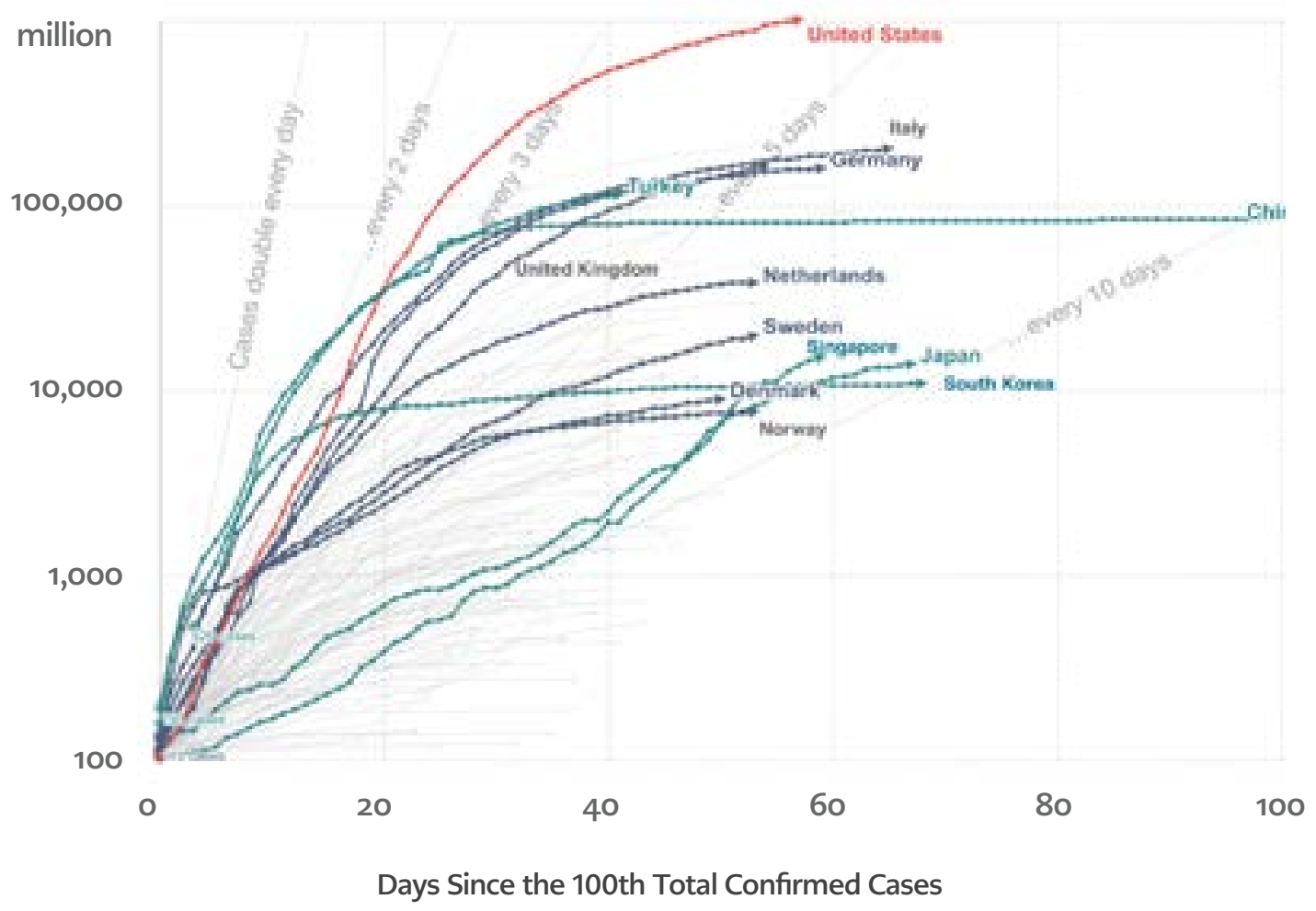

Figure 2. Total number of COVID-19 cases since the 100th confirmed case as of April 28th, 2020 (Source: Our World in Data - https://ourworldindata.org/)

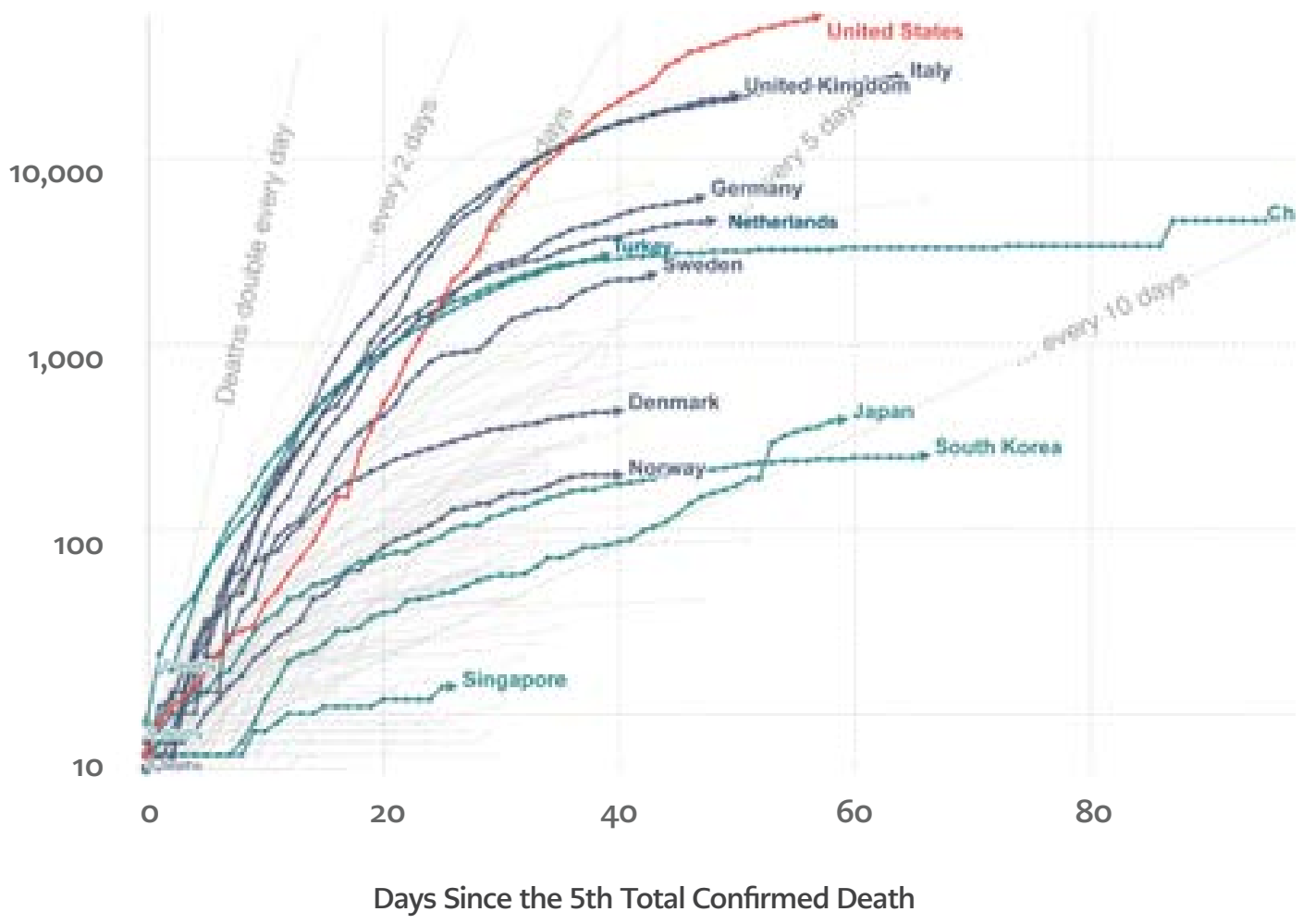

Figure 3. Total confirmed COVID-19 deaths since the 5th total confirmed death as of April 29th, 2020 (Source: Our World in Data - https://ourworldindata.org/) 
effective control during such a pandemic. On the governance level, it is of paramount importance to make decisions based on evidence, to create an infrastructure that provides quality evidence, to act in compliance with the principles of transparency and accountability, and to inform people about the latest developments by using a clear and appropriate language. While the Swedish government has decided to put the management of the outbreak in the hands of the Public Health Agency of Sweden through their evidence-based assessments, the Danish Prime Minister stated that they could not wait for evidence-based knowledge about this outbreak and that they needed to act quickly (32).

These discussions also addressed the need for a proper level of health literacy, reciprocity, and a culture of solidarity. A proper level of health literacy will enable individuals to learn about the dynamics of the outbreak, to implement the practices that will protect themselves and people around them, and to resolve the dilemmas that they encounter in the environment of infodemics by introducing the causality principle and by making use of appropriate resources (35). Individuals are expected to have reciprocity and a high level of solidarity to protect the society. Solidarity is the capacity of a society to collaborate against a common difficulty, danger or discrimination and inequalities. When people make sure that the information they share is accurate, it enables everyone to reach accurate and reliable information regarding the outbreak.

Similarly, another example could be the instance in which the people, whose opinion are that the highrisk groups should be protected in the mitigation approach, communicate with them by taking into consideration social distancing. Reciprocity on a social level is the sense of trust that the individuals who do not personally know one another will display similar behaviours in relation to a given subject. In the context of COVID-19 outbreak, individual, who avoid going to emergency wards or hospitals when there is no need, expect the same type of behaviour from the rest of the society (36).

It is important to note that both of these approaches have their disadvantages. The severe social and economic consequences of the suppression ap- proach, and its unsustainability or the requirement of rigid controlling for its continuation is its most significant disadvantage. As can be notably seen in China and Italy, these consequences have been experienced heavily $(31,37)$. It can be expected that there will be new social and health-related difficulties in the near future regarding the small businesses that go bankrupt during this process and people who become unemployed. Besides, there are also warnings about the unfavourable situations that may arise at homes due to the implementations of long-term social distancing or curfews. In households where traumatic experiences take place, since the time the parties spend together increases, the likelihood of acts of violence might increase as well (38). Mitigation approach runs the risk of leading to a high rate of mortality if the highrisk groups are not appropriately protected.

Moreover, letting the relatively healthy groups of society become ill serves as an example in which medical ethic and public health ethic come face to face. During pandemics, public health ethic generally focuses on creating criteria that will make decisions to specify the circumstances of restricting individuals' liberties and the distribution of the resources among the people in need when the resources are limited. In accordance with the ethics' principle of autonomy, it should be ensured that the individuals have a say in the decisions regarding their own bodies $(39,40)$. However, the principle of autonomy is excluded in the administrative decisions that allow the spread of the disease among a certain section of society. Therefore, allowing the virus to spread among people in a controlled manner comes to the forefront as a new question whose answer has not been discussed adequately in terms of ethics.

\section{CONCLUSION}

It is understood that given the epidemiological features of the disease, the scope of the virus, and the limitation of the intervention resources at hand, the suppression approach is accepted more widely by the countries in relation to Covid-19 pandemic. In contrast, the mitigation strategy is approached with suspicion. The approach of aiming to achieve herd immunity seems more suitable for situa- 
tions in which it is possible to protect the high-risk groups by administrating vaccine. Another point that this article has focused on is the efforts that are made so as to base those attempts for protecting public health on evidence. In this global outbreak caused by a new virus, it is expected that the evidence will change over time since not everything is known about the epidemiology of the disease and the features of the virus. However, changing policies on the basis of scientific evaluations as more is known about the virus is a good example of evidence-based policymaking as it has happened in the UK context. These evaluations should be carried out in accordance with the circumstances of the country in question. After all, what is of significance is to form an evidence-based plan that is appropriate for the national context. It should be kept in mind that the solutions for the fight against the virus do not solely consist of those ready-made implementations by choosing one option over the other and that mixed models could be brought to the agenda when required. For these evaluations, there is a need for an effective surveillance system, existence of competent people in the field of epidemiology, making use of these people, and availability of the data for usage through the principle of transparency. For disaster management, it is essential that the international data be evaluated by considering the context and that proposals be made by adopting an approach that can be attuned to the national context.
Peer-review: Externally peer-reviewed

Author Contributions: Concept - İ.K. - S.S.; Design - İ.K.; Supervision - S.S.; Funding - İ.K., S.S.; Materials - İ.K. ; Data Collection and/ or Processing - İ.K.; Analysis and/or Interpretation - I.K., S.S; Literature Review - İ.K., S.S.; Writer - İ.K., S.S.; Critical Reviews -S.S.
Conflict of Interest: The authors have no conflict of interest to declare.

Financial Disclosure: The authors declared that this study has received no financial support.

\section{REFERENCES}

1 Total lockdown would allow coronavirus to bounce back: Dutch expert. Dutch News. 2020 Mar 17 (cited 2020 Mart 24). Available from: URL: https://www.dutchnews.nl/news/2020/03/ total-lockdown-would-allow-coronavirus-to-bounce-backdutch-expert/

2 Stewart H, Busby M. Coronavirus: science chief defends UK plan from criticism. The Guardian 2020 Mar 13 (cited 2020 Apr 24). Available from: URL: https://www.theguardian.com/world/2020/mar/13/coronavirus-science-chief-defends-uk-measures-criticism-herd-immunity

3 Ferguson NM, Laydon D, Nedjati-Gilani G, Imai N, Ainslie K, Baguelin $\mathrm{M}$, et al. Impact of non-pharmaceutical interventions (NPIs) to reduce COVID-19 mortality and healthcare demand. London: Imperial College COVID-19 Response Team, March. 2020; 16 .

4 Matthews O. Britain Drops Its Go-It-Alone Approach to Coronavirus. Foreign Policy 2020 Mar 17 (cited 2020 Apr 24). Available from: URL: https://foreignpolicy.com/2020/03/17/britainuk-coronavirus-response-johnson-drops-go-it-alone/

5 Browne J, Coffey B, Cook K, Meiklejohn S, Palermo C. A guide to policy analysis as a research method. Health Promot Int 2019; 34: 1032-44.
6 Bacchi C. Analysing policy: What's the problem represented to be? Australia Pearsons 2009.

7 Paterlini M. 'Closing borders is ridiculous': the epidemiologist behind Sweden's controversial coronavirus strategy. Nature News Q\&A. 2020 Apr 21 (cited 2020 Apr 24). Available from: URL: https://www.nature.com/articles/d41586-020-01098x? utm_source=Nature+Briefing \&utm_campaign $=4525$ e04069briefing-dy-20200421\&utm_medium =email\&utm_term $=0$ _ c9dfd39373-4525e04069-43783029

8 Fine PE. Herd immunity: history, theory, practice. Epidemiol Rev 1993; 15: 265-302.

9 John TJ, Samuel R. Herd immunity and herd effect: new insights and definitions. Eur J Epidemiol 2000;16: 601-6.

10 McBryde ES, Meehan MT, Trauer JM. Flattening the curve is not enough, we need to squash it. An explainer using a simple model. medRxiv 2020. doi: https://doi. org/10.1101/2020.03.30.20048009

11 Rust G, Melbourne M, Truman BI, Daniels E, Fry-Johnson Y, Curtin T. Role of the primary care safety net in pandemic influenza. Am J Public Health 2009; 99: S316-23.

12 Lee A, Chuh AA. Facing the threat of influenza pandemic-roles 
of and implications to general practitioners. BMC Public Health 2010; 10: 661.

13 De Ceukelaire W, Bodini C. We Need Strong Public Health Care to Contain the Global Corona Pandemic. Int J Health Serv 2020:20731420916725.

14 Monella LM. Coronavirus: Italy doctors 'forced to prioritise ICU care for patients with best chance of survival'. Euronews 2020 (cited 2020 Apr 24). Available from: URL: https://www.euronews.com/2020/03/12/coronavirus-italy-doctors-forced-to-prioritise-icu-care-for-patients-with-best-chance-of-s

15 Currie CS, Fowler JW, Kotiadis K, Monks T, Onggo BS, Robertson DA, Tako AA. How simulation modelling can help reduce the impact of COVID-19. J Simul 2020:1-5.

16 Tang B, Wang X, Li Q, Bragazzi NL, Tang S, Xiao Y, Wu J. Estimation of the transmission risk of the 2019-nCoV and its implication for public health interventions. J Clin Med 2020; 9: 462.

17 Fang Y, Nie Y, Penny M. Transmission dynamics of the COVID-19 outbreak and effectiveness of government interventions: A data-driven analysis. J Med Virol 2020; 10.1002/jmv.25750.

18 Branas CC, Rundle A, Pei S, Yang W, Carr BG, Sims S, et al. Flattening the curve before it flattens us: hospital critical care capacity limits and mortality from novel coronavirus (SARSCoV2) cases in US counties. medRxiv 2020 Jan 1.

19 Hellewell J, Abbott S, Gimma A, Bosse NI, Jarvis CI, Russell TW et al. Feasibility of controlling COVID-19 outbreaks by isolation of cases and contacts. Lancet Glob Health. 2020; 8: e488-e496.

20 Roda WC, Varughese MB, Han D, Li MY. Why is it difficult to accurately predict the COVID-19 epidemic? Infect Dis Model 2020; 5: 271-81.

21 Ioannidis JP. Coronavirus disease 2019: the harms of exaggerated information and non-evidence-based measures. Eur J Clin Invest 2020; e13223. doi:10.1111/eci.13223. [Epub ahead of print].

22 Ioannidis JP, Axfors C, Contopoulos-Ioannidis DG. Population-level COVID-19 mortality risk for non-elderly individuals overall and for non-elderly individuals without underlying diseases in pandemic epicenters. medRxiv 2020 Jan 1.

23 Hanege W. I'm an epidemiologist. When I heard about Britain's 'herd immunity' coronavirus plan, I thought it was satire. The Guardian 2020 Mar 15 (cited 2020 Mar 24). Available from: URL: https://www.theguardian.com/commentisfree/2020/mar/15/ epidemiologist-britain-herd-immunity-coronavirus-covid-19

24 Rapoza K. Fearing A Second Coronavirus Outbreak, China Gets Tougher On Foreign Travelers. Forbes 2020 Mar 17 (cited 2020 Mar 24). Available from: https://www.forbes.com/sites/ kenrapoza/2020/03/17/fear-of-a-second-coronavirus-outbreak-china-gets-tougher-on-foreign-travelers/\#39d20f8c397e

25 Wei WE, Li Z, Chiew CJ, Yong SE, Toh MP, Lee VJ. Presymptomatic Transmission of SARS-CoV-2-Singapore, January 23-March 16, 2020. MMWR Morb Mortal Wkly Rep 2020; 69.

26 Hamlin C. The history and development of public health in developed countries. In Oxford Textbook of Public Health. Detels R, Gulliford M, Karim QA, Tan CC, editors. 6th ed. Oxford University Press 2015. p. 19-36.

27 Waitzkin H. Medicine and public health at the end of empire. Routledge; 2015.
28 Ünal EC. Kovid-19 nedeniyle 34.4 milyon kişi sokağa çıkamayacak. Anadolu Ajansı 2020 Apr 4 (cited 2020 Apr 18). Available from: URL: https://www.aa.com.tr/tr/koronavirus/ kovid-19-nedeniyle-34-4-milyon-kisi-sokaga-cikamayacak/1792026

29 Holligan A. Coronavirus: Why Dutch lockdown may be a high-risk strategy. BBC News 2020 Apr 5 (cited 2020 Apr 29). Available from: URL: https://www.bbc.com/news/world-europe-52135814

30 Anderson C, Libell HP. In the Coronavirus Fight in Scandinavia, Sweden Stands Apart. New York Times 2020 Mar 28 (cited 2020 Apr 18). Available from: https://www.nytimes.com/2020/03/28/ world/europe/sweden-coronavirus.html

31 Cyranoski D. What China's coronavirus response can teach the rest of the World. Nature News Explainer 2020 Mar 17 (cited 2020 Apr 24). Available from: URL: https://www.nature.com/ articles/d41586-020-00741-X

32 Moller G. Denmark and Sweden: Very different Covid reactions. Scandasia 17 Mart 2020 [Available at: https://scandasia.com/ denmark-and-sweden-very-different-covid-reactions/; Access date: 24.03 .2020$]$

33 Pisano GP, Sadun R, Zanini M. Lessons from Italy's Response to Coronavirus. Harward Business Review 2020 Mar 27 (cited 2020 Apr 29). Available from: URL: https://hbr.org/2020/03/lessons-from-italys-response-to-coronavirus

34 Lee-Wright W. Comparing Coronavirus Response in Norway \& the UK. Life in Norway 2020 Mar 18 (cited 2020 Apr 29). Available from: URL: https://www.lifeinnorway.net/comparing-coronavirus-response-norway-uk/

35 Castro-Sánchez E, Chang PWS, Vila-Candel R, Escobedo AA, Holmes AH. Health literacy and infectious diseases: why does it matter? Int J Infect Dis 2016; 43: 103-110.

36 World Health Organization. Guidance for managing ethical issues in infectious disease outbreaks. Geneva: WHO Press; 2016 (cited 2020 Mar 24). Available from: URL: https://apps. who.int/iris/bitstream/handle/10665/250580/9789241549837eng.pdf

37 Lazzerini M, Putoto G. COVID-19 in Italy: momentous decisions and many uncertainties. Lancet Glob Health 2020; doi:10.1016/S2214-109X(20)30110-8. [Epub ahead of print].

38 United Nations Women. COVID-19 and ending violence against women and girls. 2020 (cited 2020 Apr 24). Available from: URL: https://www.unwomen.org/-/media/headquarters/ attachments/sections/library/publications/2020/issue-briefcovid-19-and-ending-violence-against-women-and-girls-en. pdf?la $=e n \& v s=5006$

39 Kass N, Paul A, Siegel A. Ethical principles and ethical issues in public health. Detels R, Gulliford M, Karim QA, Tan CC, editors. Oxford Textbook of Public Health. Oxford University Press; 2015. p. 267-276.

40 UNESCO International Bioethics Committee and World Commission on the Ethics of Scientific Knowledge and Technology. Statement on COVID-19: ethical considerations from a global perspective. Document number: SHS/IBC-COMEST/COVID-19 REV. France, 2020 (cited 2020 Apr 25). Available from: URL: https://unesdoc.unesco.org/ark:/48223/pf0000373115 